\title{
European Atlas of the Seas: "a picture is worth a thousand words"
}

\author{
Vittorio Barale $^{1}$ (D) J Jean Dusart ${ }^{2} \cdot$ Michael Assouline ${ }^{1,3} \cdot$ Fabrizio Niceta $^{2,4}$
}

Received: 21 December 2016 / Revised: 28 June 2017 / Accepted: 8 September 2017 / Published online: 15 September 2017

(C) The Author(s) 2017. This article is an open access publication

\begin{abstract}
The European Atlas of the Seas offers a snapshot of environmental and socio-economic features that characterize the coastal and marine environment. The latest release (Version 4) addresses the public in general, but also nonspecialist experts involved with environmental issues, human activities or policies related to Europe's coasts and seas. The information content of the Atlas comprises a series of geographical layers, subdivided in "background maps", "thematic maps" (i.e. maritime Europe, natural setting, sea bottom, sea level rise, security, transport, tourism, energy, wind, fisheries and fish consumption) and "do-it-yourself maps" (dealing with marine knowledge, nature and environment, socio-economics, fisheries, aquaculture, transport, energy, sea bed mining, coastal tourism, Maritime Spatial Planning, integrated maritime surveillance, and international ocean governance). All maps follow consistent cartographic rules and can be extracted for external use. The Atlas database is updated regularly, but historical data remain accessible after the updates, so that time series may be constructed. Tools for map exploration and combination can be used to combine together more layers, providing professional users with analysis and interpretation capabilities, to couple data into
\end{abstract}

Vittorio Barale

Vittorio.BARALE@ec.europa.eu

1 Directorate D Sustainable Resources, European Commission, Joint Research Centre, Ispra, Italy

2 Directorate B Growth and Innovation, European Commission, Joint Research Centre, Ispra, Italy

3 Present address: European Neighbourhood Policy Activities, European Environment Agency, Copenhagen, Denmark

4 Present address: Pianificazione Territoriale, Palermo, Italy graphical indicators. The Atlas aims to supports also policy making, on marine environment, maritime issues and economic sectors, both within and outside the European Institutions (e.g. on Common Fisheries Policy or Maritime Spatial Planning). Further, it expands the same support to near-coastal issues and matters related to land-sea interactions. The web application for accessing Atlas contents offers links to other Marine Information Systems, and is available to a broad audience from computers, tablets and mobile devices.

Keywords Atlas $\cdot$ European seas $\cdot$ Coastal and marine environment $\cdot$ Maritime socio-economics

\section{Introduction}

The idiom "a picture is worth a thousand words" - which first appeared in a 1911 newspaper article published in the USA, ${ }^{1}$ and then, in varying forms, throughout various commercial advertisements in successive years - refers to the belief that an intricate notion can be easily conveyed with just a single image. Of course, the idea that a picture can express the essence of a given subject more efficiently than any lengthy description is not new, and it properly describes one of the main aims of visualization, namely making it possible to absorb very quickly large amounts of information. Geographical maps follow a similar criterion, since early times in human history: "a representation in picture of the whole known world, together with the phenomena that are contained therein" is the definition of a map provided by the Greek scholar Ptolemy, Cluadius Ptolomeus, as early as the second century A.D. in his seminal work Geographia, also known by the title Cosmographia (Berggren and Jones 2000).

\footnotetext{
${ }^{1}$ According to WIKIPEDIA, the free encyclopaedia, consulted on November 2nd, 2016.
} 
The same notion underpins the European Atlas of the Seas, a web-based information system recently developed and currently maintained by the European Commission (EC). In the view expressed by the "Blue Paper" (European Commission 2007) that launched the Integrated Maritime Policy (IMP) ${ }^{2}$ of the European Union (EU), the Atlas' collection of maps and related fact sheets - based on data originating primarily, if not exclusively, from the EC and its Agencies - were to present a snapshot of the key environmental and socio-economic elements that characterize the coastal and marine environment of the EU Member States (MS) and their Outermost Regions. However, what was originally foreseen as a mere publicoriented communication and education tool, today has evolved into a significant experiment of knowledge brokerage in the marine world, mediating between the research domain and a varied group of practitioners, interested in having simplified access to highly specialized information. The overall approach is to convert complex scientific data about coasts, seas and oceans into graphical form, so that non-specialists may use (and overlay, combine, or fuse) the available products, without having to transfer or process large amounts of data, tasks that might require ad hoc technical skills often unavailable (Barale et al. 2015).

The EC Directorate General (DG) for Maritime Affairs and Fisheries (MARE) conducted initial conceptual work on the European Atlas of the Seas in 2008, while the actual system architecture and the original infrastructure, data collection, map services and descriptive texts were developed in 2009. A first prototype of the Atlas was published on the web in 2010, and underwent a public consultation and a user survey in the same year. The 2011 release of Version 1 of the Atlas, covering 50\% more contents than the prototype (i.e. around 70 thematic maps) was followed at the end of 2012 by that of Version 2, offering better performance and interoperability, and in early 2013 by that of an enhanced Version 2.1, hosted by the European Environment Agency (EEA). Through an agreement with DG MARE, the Joint Research Centre (JRC) of the EC was assigned the task to develop first an expanded Version 3, targeting both the general public and professionals, in the period 2013-2014, and then a technically advanced Version 4, addressing new requirements of an enlarged targeted audience (including policy makers and stakeholders), in the period 2015-2016, with the aim to foster the development of new features and services, as well as the interaction with other information access tools either available or planned.

The conceptual design of internet-based information systems dealing with the coastal and marine environment had

\footnotetext{
$\overline{2}$ The Integrated Maritime Policy (IMP) aims at a coherent approach to maritime issues and to an increased harmonisation of different policy areas, focusing on multi-sector economic development, i.e. "blue growth", and on the cooperation of different sectors and actors, e.g. on "marine knowledge". More details can be found at the web address: http://ec.europa.eu/ maritimeaffairs/policy/index_en.htm.
}

made its first appearance at the JRC already in the early 1990's (Barale 1991). Within a decade, on-line access to satellite-derived numerical and pictorial data, focusing on the European Seas, was made available by virtue of dedicated web pages and simple data exploration tools (Barale et al. 1999). These initial developments led to the publication of the Environmental Marine Information System (EMIS), ${ }^{3}$ based on both satellite data and numerical model outputs, and geared to facilitate access to a suite of data products that would interest primarily the scientific community. The current version of EMIS includes mapping tools delivering information by way of custom-made, geo-referenced charts, created in real time, and supplies users with basic navigation and interrogation tools for regional assessments. The same data concept supports the EMIS-R Marine Analyst, ${ }^{4}$ a web-based tool dedicated to the environmental assessment (based on existing data sets published in EMIS) of special marine areas such as Marine Protected Areas (MPAs) and other political assessment units, in support of the the Marine Strategy Framework Directive (Anonymous 2008). Following this approach, the EC's European Atlas of the Seas was upgraded to improve availability of both environmental and socio-economic data, and to provide a suite of ready-made instruments for the evaluation of coastal and marine issues. Unlike earlier releases, the new version of the Atlas not only provides a reference point for the public in general, but also is also capable of helping nonspecialist professionals involved with environmental issues, human activities or policies related to Europe's coasts and seas.

When delineating the Atlas of the Seas transition from Version 3 to the very latest Version 4, described in some detail in the following sections, DG MARE and the JRC started reflecting on the future Atlas' content and how it could be further developed taking into considerations new user communities' priorities (and in particular those priorities emerging from other European Institutions and Services). The resulting vision set the scene for the new system development, focused onto the following EU policy-related issues:

Marine Knowledge. Substantial progress has been made in harmonizing and assembling Europe's marine and maritime data for scientists and engineers through the "Marine Knowledge 2020" initiative - due to DG MARE, DG Environment (ENV), DG for Research and Innovation (RTD), DG for Internal Market, Industry, Entrepreneurship and SMEs (GROW) and the JRC - according to which, for a broader audience to benefit of

\footnotetext{
3 The system is currently available at: http://emis.jrc.ec.europa.eu/. A somewhat expanded version, the Global Marine Information System (GMIS) , offering slightly different features, but covering the entire world's oceans, is available at: http://gmis.jrc.ec.europa.eu/.

${ }^{4}$ Available within the website of the Marine Strategy Framework Directive (MSFD) Competence Centre, also developed and maintained by the JRC, at the address: http://mcc.jrc.ec.europa.eu/.
} 
current capabilities, scientific and technical knowledge needs to be made more understandable, accessible and useable (European Commission 2012a).

Sea-basins strategies. In order to extend inter-regional cooperation and finance macro-regional or sea-basin strategies, DG MARE, DG RTD, DG for Regional and Urban Policy (REGIO) and a score of other stakeholders need harmonized information, such as those offered by the Atlas, to provide a consistent view of knowledge related to Europe's seas and coasts, and to allow comparative analysis, tracking of advances, as well as accessibility of information on the geographic distribution and economic potential of maritime industries and/or EU-funded projects, on topics like marine biotechnology, seabed mining, ocean energy, coastal tourism, aquaculture.

Scientific advice on fisheries. In the realm of supporting maritime economic activities, the Atlas should contribute in particular to making fisheries matters more accessible, for example by translating technical reports and indicators related to the state of fish stocks in European waters, and the scientific advice associated with the management of their exploitation, into easy to understand maps and figures. Another example would be that of mapping the geographical spread-out of multiannual fisheries plans (existing and planned). To support DG MARE activities, and in particular the EU Common Fisheries Policy (CFP), the Atlas could report European Maritime and Fisheries Fund (EMFF) financial allocations per MS, and the foreseen (2014-2020) spending per EU priority, or again it could chart the Sustainable Fisheries Partnerships Agreements (SFPA) that allow EU fleets to fish in third countries.

Maritime Spatial Planning (MSP). With the 2014 entry into force of the MSP Directive (Anonymous 2014), the EU MS are stepping up efforts to plan use of their seas. By monitoring progress and disseminating results of MSP processes, by facilitating sharing of best practice and by showing maps indicating the designated uses of marine spaces, the Atlas will allow DG ENV to consider advancements in protecting the sea, DG for Energy (ENER) to assess where space has been reserved for offshore renewable energy, and DG MARE to evaluate whether objectives in increasing space for aquaculture have been achieved.

Support to related initiatives. Information collected during EU-funded, finite-duration research and development projects is often lost once a project stops. For instance, DG ENV has collected material on ongoing and past projects on coastal management under the OURCOAST initiative, in order to help MS see what has been done elsewhere in the EU (European Commission 2012b). The OURCOAST database considered for the Atlas contains 363 case studies that have been geo-localized and classified. Each presents information such as title, start/end date, status (depending if the project is ongoing or closed), location, theme, brief description and links to the full case studies' reports and other background documents. Such information could be maintained by and distributed through the Atlas.

In the following, the basic technical details about the Atlas latest version's infrastructure will be provided, together with a description of the current Atlas contents' composition. The emerging picture is that of a somewhat revolutionary project, the real value of which lies in the unprecedented collaborative effort between many partners, in various jurisdictions, to put together an interactive cartographic system that meets the public's needs to share information about marine resources in the EU. The various partnerships and associations constituting the main strength of the Atlas will be highlighted, and the unique opportunities for data access and analysis, offered by this cooperative endeavor between EU MS and Institutions, described in some detail.

\section{The Atlas of the Seas infrastructure (version 4)}

The current European Atlas of the Seas infrastructure is based on the Environmental Systems Research Institute (ESRI ${ }^{\mathrm{TM}}$ ) stack, including the ArcGISTM Application Programming Interface (API) for JavaScript ${ }^{\mathrm{R}}$ and ArcGISTM Server. ${ }^{5}$

The new developed portal for the Atlas' Version 4 (V4) uses a seamless combination of some Languages and Frameworks thought and provided for the Web. These are:

HTML5 and CSS3 for the graphical structure JavaScript Language for the core and all functions JQuery Framework for Graphical effects and functions improvements

Dojo Toolkit framework for the interaction with the Document Object Model (DOM) for mobile applications.

The Atlas' V4 has all the features that were present in the previous version, but with the development of the new API provided by ESRI ${ }^{\mathrm{TM}}$ these functions were improved to give a better navigation experience to the users across maps and layers information.

For the server side infrastructure, around 120 map services - standard protocols for serving geo-referenced map images over the Internet, which are generated by a map server using data from a GIS database (Scharl and Tochtermann 2007) - are currently displayable in the Atlas. The major part of these map services are published using an ArcGIS ${ }^{\mathrm{TM}}$ Server instance devoted specifically for this purpose (and hosted by the EEA). These map

\footnotetext{
${ }^{5}$ Full documentation on these Information Technology (IT) elements is available at: http://support.esri.com/en/.
} 
services ${ }^{6}$ can be re-used by external applications by means of the ESRITM Representational State Transfer (REST) API, the Keyhole Markup Language (KML) format (Wilson 2008) or the Open Geospatial Consortium (OGC) Web Map Service (De la Beaujardiere 2006). Additionally, some map services published by external partners (i.e. Eurostat, EEA and ESRI ${ }^{\mathrm{TM}}$ map services) are systematically re-used. The Atlas is therefore a de facto aggregator of external map services, reinforcing its distributed nature.

For the client side infrastructure, the Atlas' V4 cartographic interface (see Fig. 1) is based on the ArcGISTM JavaScript ${ }^{\mathrm{R}}$ viewer. It provides basic functionalities such as panning and zooming, map layer selection, legend display and object selection. A time slider is used to scroll through temporal data across time. With respect to previous versions, the new interface includes, among other features, the following items:

map generation tools, to allow users to better specify and export a map;

two user profiles: "thematic" (general public) and "do-ityourself" (advanced users);

improved interactivity, using innovative mapping techniques (Gaffuri 2012);

temporal visualisation, to display animated maps and graphics with a time dimension.

In order to improve the communication between the users and the developers of the Atlas, a user's feedback collection tool is available to send feedback messages. An information news feed on the Atlas evolution is also available for the regular users.

\section{The Atlas of the Seas composition (version 4)}

The European Atlas of the Seas offers global coverage for a number of marine and maritime parameters, but is specifically focused on the European marginal and enclosed seas (i.e., Mediterranean Sea, Black Sea, Baltic Sea, North Sea, Celtic Seas, Bay of Biscay, and Atlantic Iberian Coast), as well as the EU Outermost Regions (i.e., waters surrounding the Azores, Madeira and Canary Islands; plus French Guiana, Martinique, Guadeloupe, and Saint Martin in the Atlantic Ocean; as well as Mayotte and La Réunion in the Indian Ocean). When appropriate, for instance in the case of the international Sustainable Fisheries Partnership Agreements (SFPA), it presents also details of treaties geographically located outside the EU. The general appearance of the viewer welcoming users to the Atlas, showing a map of the marine regions of Europe according to the

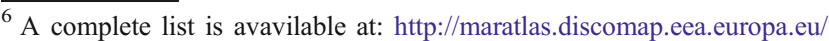
arcgis/rest/services/Maratlas .
}

boundaries adopted by EU MS, ${ }^{7}$ is illustrated in Fig. 1. The information content of the Atlas is composed by a series of geographical layers, mirroring the main themes relevant for the IMP of the EU, subdivided in "background layers", "thematic maps" and "do-it-yourself maps". All texts related to these data layers and maps are available in three languages, namely English, French and German.

The main sources of data for the Atlas are the EC institutions $^{8}$ and other bodies. ${ }^{9}$ Several EC-funded programmes, projects and networks, ${ }^{10}$ initiated directly under the auspices of either the EC Services and Agencies above, or other national governmental agencies and commercial companies from the EU and European Free Trade Association (EFTA) Countries ${ }^{11}$ or non-EU Countries, ${ }^{12}$ also play a major part in populating the Atlas database. In addition, contributions are provided by a number of international associations and institution, ${ }^{13}$ as well as various United Nations (UN) bodies. ${ }^{14}$ In the Atlas, the information source is reported in full detail together with the metadata that accompany each map.

Four "background maps", provided by ESRITM as ArcGISTM map services, ${ }^{15}$ are included in the Atlas to deliver basic

\footnotetext{
${ }^{7}$ Adoption of the Marine Strategy Framework Directive (MSFD) Committee of November 10th, 2016. The map results from coordination across the EU legislation taking into account MSFD, Maritime Spatial Planning Directive as well as the nature directives. Further, the boundaries of the regions have been aligned, where feasible, with the boundaries of the Regional Sea Conventions. ${ }^{8}$ i.e. DG Energy (ENER), Environment (ENV), Joint Researcg Centre (JRC), Maritime Affairs (MARE), Mobility \& Transport (MOVE), Eurostat (ESTAT) Geographic Information System of the Commission (GISCO).

${ }^{9}$ i.e. the European Environment Agency (EEA), European Maritime Safety Agency (EMSA), European Fisheries Control Agency (EFCA), European Market Observatory for Fisheries and Aquaculture (EUMOFA).

${ }^{10}$ e.g. the European Fisheries Areas Network (FARNET), bringing together Fisheries Local Action Groups (FLAGs) and implementing Community-Led Local Development (CLLD) under the European Maritime and Fisheries Fund (EMFF), or the Coordination of Information on the Environment' (CORINE) Programme.

11 e.g. VLIZ Marineregions.org, IGN, Swisstopo, AeroGRID.

12 e.g., various US Agencies, such as USDA, USGS, NOAA, NGIA, associations, like National Geographic and GeoNames, or companies such as ESRI, DigitalGlobe, DeLorme, i-cubed, NAVTEQ/HERE.

13 among which the Association of the European Cadastre, Land Registry and National Mapping Authorities (EuroGeographics); the European Maritime Heritage (EMH); the General Bathymetric Chart of the Oceans (GEBCO); the International Aquarium Forum (IAF); the International Council for the Exploration of the Sea (ICES); the International Hydrographic Organization (IHO); the International Tanker Owners Pollution Federation (ITOPF); and the International Union for Conservation of Nature (IUCN).

14 the United Nations Educational, Scientific and Cultural Organization (UNESCO); the United Nations (UN) Food and Agriculture Organization (FAO) and International Maritime Organization (IMO).

${ }^{15}$ Maps compiled from a variety of sources from several data providers, including the US Environmental Protection Agency (EPA), Geological Survey, National Oceanic and Atmospheric Administration (NOAA), National Park Service (NPS), USDA, USGS; the Department of Natural Resources Canada (NRCAN) and Agriculture and Agri-Food Canada; the Food and Agriculture Organization (FAO) of the United Nations; the General Bathymetric Chart of the Oceans GEBCO_08 Grid; National Geographic; companies and consortia such as AeroGRID, CNES/Airbus DS, DeLorme, DigitalGlobe, Earthstar Geographics, GeoBase, GeoEye, Geonames.org, HERE, IGN, OpenStreetMap; ESRITM, the GIS User Community, and other contributors.
} 


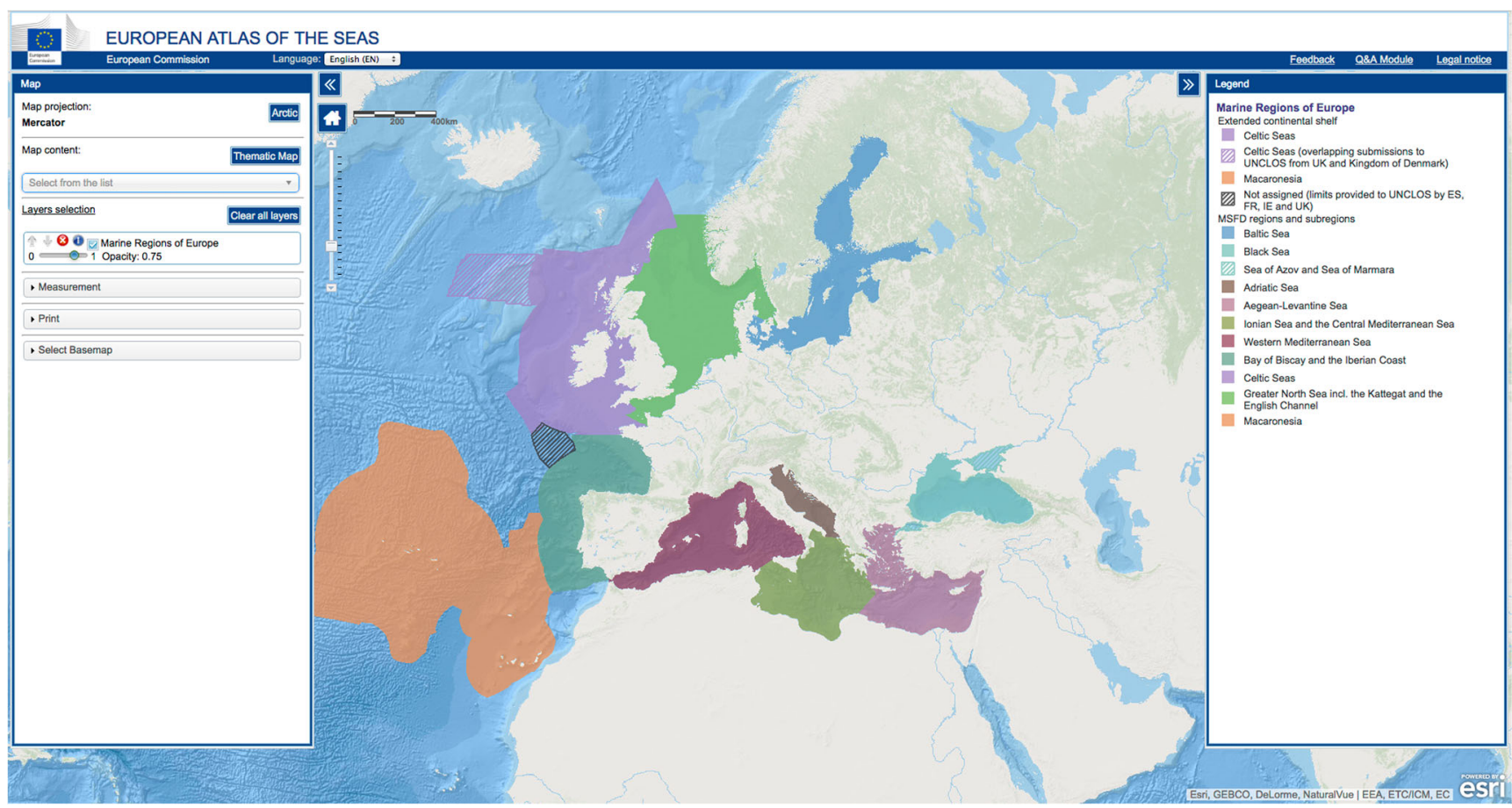

Fig. 1 European Atlas of the Seas viewer, showing a map of the marine regions of Europe according to the boundaries adopted by the EU Member States

information on the sites of interest, and to be displayed as a neutral background for other maps (see Fig. 2). The Base Template data layer ${ }^{16}$ offers worldwide coverage of shaded relief imagery, bathymetry, and coastal water features, down to a scale of $\sim 1: 1000,000$. The Water Template data layer ${ }^{17}$ shows marine bathymetry and inland waters, at variable regional scales, overlaid on land cover and shaded relief imagery. The Ocean Reference data layer ${ }^{18}$ comprises administrative boundaries, cities, water features, physiographic features, parks, landmarks, highways, roads, railways, and airports, overlaid on land cover and shaded relief imagery, covering the world down to a scale of $\sim 1: 72,000$ (or 1:4000, 1:2000 and 1:1000 for selected areas). The Civil Template data layer ${ }^{19}$ presents both high-resolution (1 m or better) satellite and aerial images, for selected parts of the world, and low-resolution satellite images elsewhere.

The Atlas, in view of its education and communication mission toward the general public, provides a series of ready-made "thematic maps". These pre-conceived composite maps (see e.g. Figure 3) present a comprehensive view of the most popular themes that emerged from the viewing statistics of the Atlas' earlier versions, i.e. natural setting, sea bottom, sea level rise, security, transport, tourism, energy, wind,

\footnotetext{
${ }^{16}$ details at: http://server.arcgisonline.com/arcgis/rest/services/World_ Terrain_Base/MapServer

${ }^{17}$ details at: http://server.arcgisonline.com/arcgis/rest/services/Ocean/World Ocean_Base/MapServer

18 details at: http://server.arcgisonline.com/ArcGIS/rest/services/World Topo_Map/MapServer

19 details at: http://server.arcgisonline.com/ArcGIS/rest/services/World Imagery/MapServer
}

fisheries and fish consumption. The aim of this group of maps is to cater to the needs of unskilled users, who simply want to learn more about a number of standard popular topics, mapped together in a concise way.

Further to background layers and thematic maps, a large number of "do-it-yourself maps" are included in the Atlas, relating to natural and socio-economic elements of the European oceans, marginal seas and coastal regions (see e.g. Figure 4). The name of this section of the Atlas recalls the potential of all its data layers to be combined and displayed together, thereby allowing professional users to explore information contents and relations, and to construct their own indicators' maps. The Atlas' graphical features allow users not only to set up specific composite maps of interest, but also to save, download and reproduce the results of their data exploration in successive reports. The data layers available for this purpose - stored as time series, when appropriate or feasible, and updated on a regular basis - are classified under eleven main categories (i.e. the IMP themes recalled above), which can be detailed as follows:

the "marine knowledge" category provides basic information on EU countries, basins, bathymetry (depth \& relief names), coastlines (land cover and infrastructures), hydrography, drainage basins, EMODnet partners and links to other regional atlases;

the "nature \& environment" category includes oceanographic parameters, sea level change, coastal erosion, land cover, Large Maritime Ecosystems (LME,) international conventions, protected areas and Natura 2000 sites; 


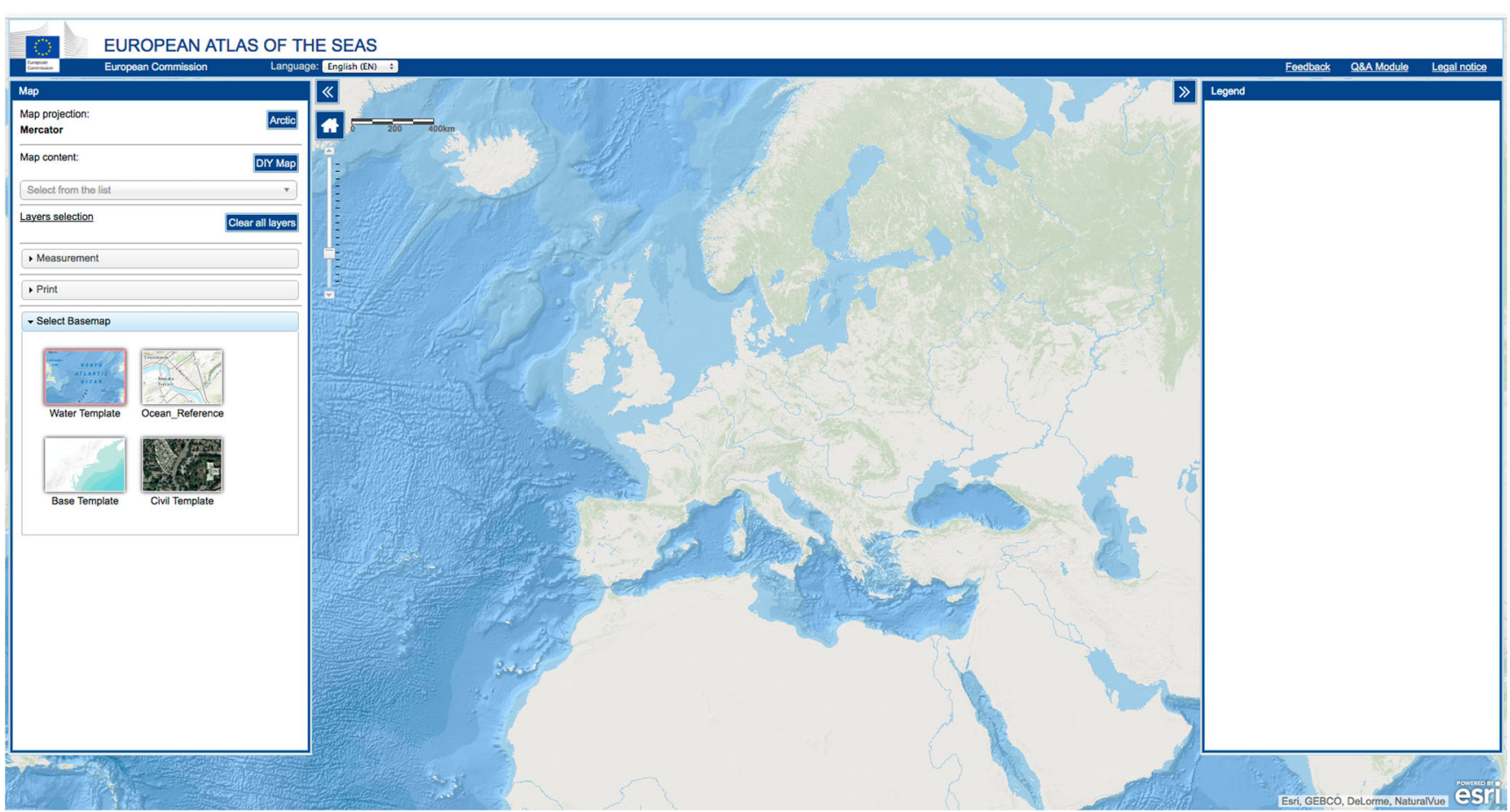

Fig. 2 European Atlas of the Seas "background layer", showing shaded relief and bathymetry, developed by ESRI Inc.

the "socio-economics" category provides demographic and economic statistics for coastal regions, i.e. Gross Domestic Product (GDP), maritime impact, population density, population changes, active population and other age groups, urban-rural typology, employment and unemployment by sector; the "fisheries" category provides layers on fish stocks, fishing fleets (number of vessels, engine power, tonnage), fishing ports, fishing zones (ICES and FAO), quotas (by countries, fishing zones and species) and catches (by countries and by fishing zones); production, processing facilities, consumption and trade (volume and value); employment,

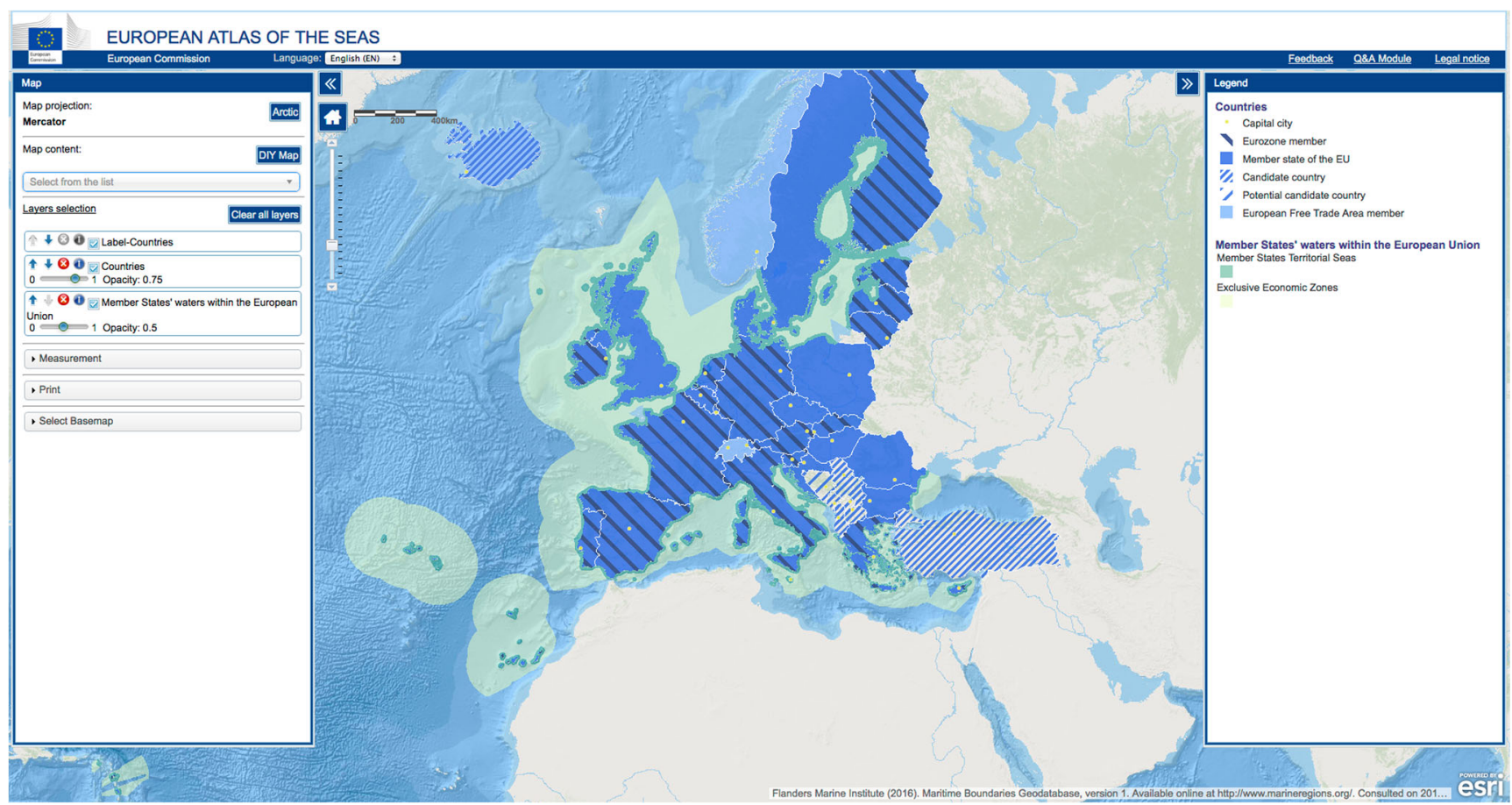

Fig. 3 European Atlas of the Seas "thematic map" on maritime Europe (i.e. EU Member States and their territorial waters - or Exclusive Economic Zones - as detailed in footnote no. 7), showing the kind of data combination presented in a composite map for the general public 


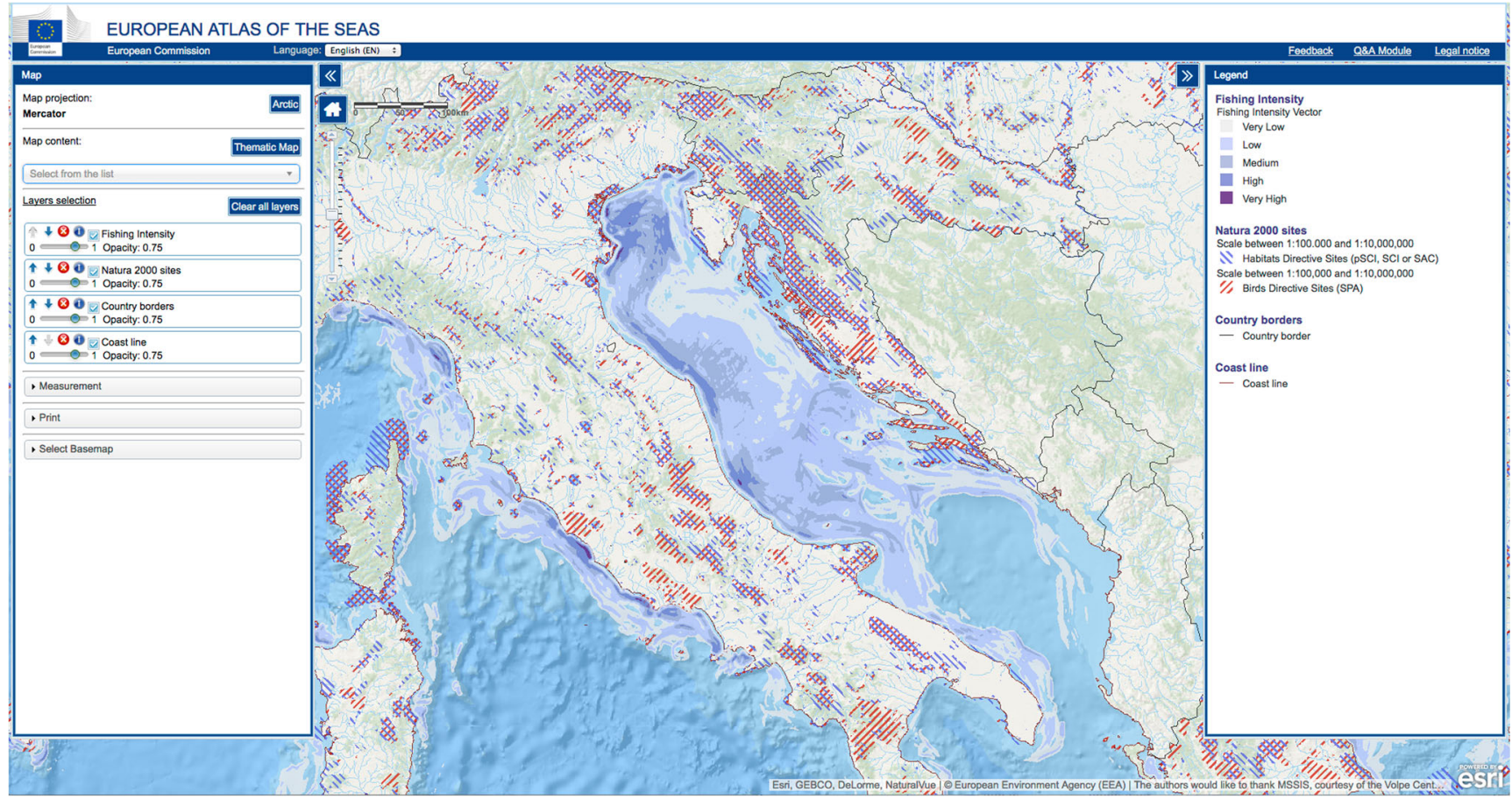

Fig. 4 European Atlas of the Seas "do-it-yourself map" centered over the Adriatic Sea, showing (coastlines, country borders and) fishing intensity vs marine protected areas (Natura 2000 sites). This map provides an example of the novel merging of data that can be achieved by professional users,

Fisheries Local Action Groups (FLAGs), regional fisheries management (highly-migratory and non-highly-migratory species), producers organizations, advisory councils; under the same heading, the "aquaculture" category covers total production and production by species;

the category on "transport" offers layers on ports, ferry routes, motorways of the sea, shipping (i.e. transported passengers and goods, by port and route);

the category on "energy" covers average wind speed and direction, wave height and direction, tidal amplitude, marine energy production facilities, offshore wind farms (existing and planned);

the category on "sea bed mining" shows undersea relief (names), seabed sediments and deep-sea mineral resources; the "coastal tourism" category deals (primarily) with coastal environment (e.g. coastal geology, as well as state of bathing waters) and coastal infrastructures (e.g. accommodation offered, as number of beds per $\mathrm{km}^{2}$ ), but covers also UNESCO world heritage sites, maritime museums and aquariums;

the "MSP" category provides layers on maritime spatial plans and project test sites, and with available coastal and marine atlases;

the "integrated maritime surveillance" layer maps current surveillance projects and plans;

the "international ocean governance" category deals with political aspects of maritime affairs: MS waters within the combining together classical spatial data on nature conservation sites and the latest data on areas of intense exploitation of natural resources, like those described by fishing intensity in the Adriatic Sea

EU, Conference of Peripheral Maritime Regions, Regional Advisory Councils, European Maritime Day.

The total volume of all these layers - which include raster and vector marine data, as well as coastal data organized according to the Nomenclature of Units for Territorial Statistics (NUTS) hierarchical system, ${ }^{20}$ a geocode standard developed to sub-divide the EU MS for statistical purposes - reaches several GB. All maps follow consistent cartographic rules and can be extracted for external use. A progressive degree of simplification is adopted for small-scale visualisations, while more detailed data are used for large-scale visualisations.

The collection of maps provided by the European Atlas of the Seas presents a broad outline of natural and socioeconomic features in the marine and coastal regions of the European continent. The Atlas database is updated regularly with the latest releases from each provider. Automatic update procedures have been developed to ensure a quick upload from the different data sources. For most thematic layers, historical data remain accessible after the updates, so that time series may be constructed, to visualise the evolution of an indicator over a given period. The database may be enlarged with the addition of ancillary layers covering new themes, in

\footnotetext{
${ }^{20}$ For details see: http://epp.eurostat.ec.europa.eu/portal/page/portal/nuts nomenclature/introduction.
} 
particular when relevant to the "blue economy" (i.e. foreseen in the EC Blue Growth Strategy ${ }^{21}$ ), like maritime transport, mineral or living resources, climate change and new biotechnologies.

Tools for map exploration and combination can be used to extract ad hoc indications on various themes from each data layer, or to combine together more layers for a comparative look at the same themes. As seen earlier, the basic idea behind these characteristics of the Atlas is that of providing non-specialist, but professional users with analysis and interpretation capabilities, to couple data into ecological and/or socio-economic indicators. Rather than aiming to be a mere geographic data catalogue, therefore, the Atlas is conceived both as an easy access point to marine and maritime datasets (providing suitable coordinates of the websites from which original data can be downloaded, if required), organized into a Geographic Information System (GIS), and as a generator of high-quality, complete, thematic representations, for professionals in the maritime sector, European policy-makers and of course citizens at large.

\section{Conclusion}

The European Atlas of the Seas remains essentially a publicly accessible web-based source of spatial data. As such, it conveys relevant, easy-to-access and easy-to-understand information at the fingertips of stakeholders in the EU Institutions, to environmental administrations and bodies, to professionals in various maritime sectors (including fisheries, transport, energy) and other types of organizations (e.g. private companies, nongovernmental organizations, academia), and of course to the wider public. In particular, the Atlas supports policymaking on marine environment, maritime issues and economic sectors, both within and outside the EC, by providing digital, thematic, composite maps of European seas and coasts. The availability of this wealth of information is expected to have a distinct positive effect on EU rules and strategies related to all marine and maritime matters, in particular when the Atlas beneficiaries are policy-makers.

Examples of research innovations set for policy support are those linked to the Common Fisheries Policy (CFP) and to MSP. In the first case, the Atlas' maps and charts are offering a new integrated approach to fisheries research results, previously available only in lengthy reports, aiming to improve data display and analysis and to monitor progress of policy implementation. Users are offered the unique opportunity to visualize, interrogate and compare on a single platform a lot of information related to fisheries - e.g. to associate the state of fish stocks in Europe with the total amount

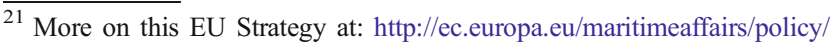
blue growth/index en.htm.
}

of catches and/or landings, in time, or to visualize the EMFF operational programs of each MS, and link the different MS priorities and allocations. In the second, the Atlas' EU-wide thematic map collection delivers a common baseline that can help MS getting started on the MSP Directive requirements. As this is widely seen as a pre-requisite for Blue Growth, future research extending current projects results and facilitating MSP applications will help combine protection and sustainable use of the European Seas' ecosystem resources. The Atlas expands the same support also to near-coastal issues and issues related to land-sea interactions (e.g. by providing data layers on coastal land use, bathing waters, coastal geology and erosion, river basins, coastal winds, waves and tides, ports, coastal infrastructures and various economic activities, and by incorporating the entire OURCOAST $^{22}$ database).

As a policy support tool, the Atlas informs decisionmaking at all EU, national and regional levels. It aims to contribute to the Group on Earth Observations (GEO) Blue Planet Initiative, ${ }^{23}$ on the global scale, and to the implementation of the Transatlantic Ocean Research Alliance, ${ }^{24}$ on the regional scale. In doing so, it facilitates a shared understanding of various aspects (natural, environmental, societal) of the European seas and their coastlines, which becomes accessible from computers, tablets and mobile devices, understandable to a broad audience (decision makers, stakeholders, public), and continuously updated with data from a number of different sources.

The Atlas makes use of publicly available datasets from European Union institutions and bodies and selected data providers. Marine data assemblage and dissemination is carried out in a transparent manner. There are no duplications of efforts with other initiatives such as those of EMODnet, ICES or the Regional Sea Conventions, which remain the responsible entities for marine data collection. Thus, data creation and management are left with the source organizations. Analysis and processing of data and information are required for inclusion in the Atlas, to provide an operational solution to DG MARE requirements and to render marine and maritime knowledge easily accessible to all potential users. This makes use of new software tools or adaptations of existing software, and is baked by documentation of processes and workflows for data ingestion and updates. Much work has been devoted to the development of a public web application for accessing Atlas content, with links to other Marine Information Systems. Similarly, the development of a restricted web application allows retrieving Atlas content and

\footnotetext{
${ }^{22}$ For details see OURCOAST: the European portal for Integrated Coastal Zone Management, at: http://climate-adapt.eea.europa.eu/metadata/portals/ ourcoast-the-european-portal-for-integrated-coastal-zone-management

${ }^{23}$ For details see http://geoblueplanet.com/.

${ }^{24}$ As described in: http://ec.europa.eu/research/iscp/index.cfm?pg= transatlantic-alliance.
} 
specific layers that demand access restrictions. A collaborative platform (WIKI) is available for data documentation and management of user feedback. Atlas-related activities include training and capacity building, as well as the production of promotional material and on-line tools for user assistance.

The European Atlas of the Seas is poised to become an even more advanced visualization and mapping tool, in the framework of the current effort to simplify and streamline the plethora of Marine Information Systems available online. The many initiatives in this field, either dealing with a holistic view of the sea or with specific maritime sectors, are a symptom of an unanswered requirement by a wide user community. Most of the current initiatives would benefit from a unifying element, such as the Atlas is becoming, to ensure substantial savings in organizing and delivering data, and giving a second life to past scientific projects. Ultimately, the Atlas aims to help policy-makers and other stakeholders at large cope with the incumbent data, information and knowledge overload, providing expertise in the use of modern, analytical tools.

Acknowledgements The present paper stems from activities carried out at the European Commission (EC) Joint Research Centre (JRC) in the framework of Administrative Arrangement S12.706169 with the EC Directorate General (DG) for Maritime Affairs and Fisheries (MARE). The authors wish to express their gratitude to the many Colleagues from the JRC, and from other EC Services and Agencies, simply too numerous to be listed here, who contributed one way or the other (mostly the other) to gathering the information above and elaborating the concepts presented in this paper. In particular, thanks are due to the DG MARE Colleagues, and especially to A.F. Woestyn, who led early developments of the European Atlas of the Seas. The European Environment Agency (EEA) has been, and still is, hosting the Atlas on its servers, and offered constant support for its maintenance. Thanks are also due to two anonymous reviewers, for their helpful contributions.

Open Access This article is distributed under the terms of the Creative Commons Attribution 4.0 International License (http:// creativecommons.org/licenses/by/4.0/), which permits unrestricted use, distribution, and reproduction in any medium, provided you give appropriate credit to the original author(s) and the source, provide a link to the Creative Commons license, and indicate if changes were made.

\section{References}

Anonymous (2008) Directive 2008/56/EC of the European Parliament and of the Council of 17 June 2008 establishing a framework for community action in the field of marine environmental policy (Marine Strategy Framework Directive). Off J Eur Union L 164(25.6.2008): 19-40

Anonymous (2014) Directive 2014/89/EU of the European Parliament and of the Council of 23 July 2014 establishing a framework for maritime spatial planning. Off J Eur Union L 257(28.8.2014):135-145

Barale V (1991) Marine remote sensing information system (MARSIS): a conceptual design. Int J Remote Sens 12(4):795-802

Barale V, Larkin D, Fusco L, Melinotte JM, Pittella G (1999) OCEAN project: the European archive of CZCS historical data. Int J Remote Sens 20(7):1201-1218

Barale V, Assouline M, Dusart J, Gaffuri J (2015) The European Atlas of the Seas: relating natural and socio-economic elements of coastal and marine environments in the European Union. Mar Geod 38:79-88

Berggren JL, Jones A (2000) Ptolemy's Geography: an annotated translation of the theoretical chapters. Princeton University Press, Princeton and Oxford

De la Beaujardiere J (Ed) (2006) OpenGIS® Web Map Server Implementation Specification. Document OGC® 06-042, V. 1.3.0. Open geospatial consortium Inc, Wayland

European Commission (2007) Communication from the Commission to the European Parliament, the Council, the European Economic and Social Committee and the Committee of the Regions - An Integrated Maritime Policy for the European Union ("the Blue Book"). COM (2007) 575 final, Publications Office of the EU, Luxemburg, pp 12

European Commission (2012a) Green Paper - Marine Knowledge 2020 from seabed mapping to ocean forecasting. COM (2012) 437 final, Publications Office of the EU, Luxemburg, pp 23

European Commission (2012b) Integrated coastal zone management: OURCOAST outcomes and lessons learned. Publications Office of the EU, Luxemburg, pp 36

Gaffuri J (2012) Toward web mapping with vector data. In: Xiao N, Kwan M-P, Goodchild MF, Shekhar S (eds) Geographic Information Science, Lecture Notes in Computer Science, vol 7478. Springer, Berlin, pp 87-101

Scharl A, Tochtermann K (2007) The Geospatial Web: How Geobrowsers, Social Software and the Web 2.0 are Shaping the Network Society. Springer, London

Wilson T (Ed) (2008) OGC® $K M L$. Document OGC® 07-147r2, V. 2.2.0. Open geospatial consortium Inc, Wayland 